\title{
A ASSISTÊNCIA DO TERAPEUTA OCUPACIONAL PARA PESSOAS COM ANOREXIA NERVOSA: RELATO DE EXPERIÊNCIA
}

\author{
ASSISTANCE PROVIDED BY THE OCCUPATIONAL THERAPIST TO PERSONS \\ WITH ANOREXIA NERVOSA: REPORTS OF EXPERIENCE
}

Luciene V Morais

Terapeuta Ocupacional. Serviço de Terapia Ocupacional Hospitalar. Hospital das Clínicas da FMRP-USP. Doutoranda. Faculdade de Filosofia, Ciências e Letras de Ribeirão Preto- USP. Docente. Centro Universitário Claretiano de Batatais.

CorResPondência: Rua Amadeu Amaral, 455. Vila Seixas. CEP 14020-050 Ribeirão Preto - SP. E-mail: Ivaccaro@usp.br

Morais LV. A assistência do terapeuta ocupacional para pessoas com anorexia nervosa: relato de experiência. Medicina (Ribeirão Preto) 2006;39 (3): 381-5.

RESUMO: Os transtornos alimentares têm sido foco da atenção dos profissionais da área da saúde por apresentarem significativos graus de morbidade, mortalidade, prejuízo pessoal e social. Desde o ano de 1999, a terapeuta ocupacional do Serviço de Interconsulta em Saúde Mental do Hospital das Clínicas da Faculdade de Medicina de Ribeirão Preto-USP realiza assistência aos pacientes com transtornos alimentares que se encontram em regime de internação hospitalar. Na maioria das vezes, esta assistência é ampliada para familiares e equipe, objetivando ações conjuntas e complementares nas diversas situações conflitivas. A clientela predominante é constituída por mulheres adolescentes e jovens, apresentando quadro de anorexia nervosa e em sua maioria, com dificuldade na organização e no desempenho das atividades da vida cotidiana, seja pelos comprometimentos clínicos ou pelos prejuízos emocionais e sociais. Não é raro apresentarem um cotidiano restrito, com afastamentos do trabalho, dificuldades nos relacionamentos interpessoais, na realização de atividades do dia-a-dia e em casos graves, a desvinculação dos papéis sociais e profissionais. Tendo em vista seu campo de conhecimento e de assistência, a terapia ocupacional para pessoas com anorexia nervosa proporciona um espaço de vivência e discussão para os conflitos relacionados à imagem corporal distorcida, ajuda no resgate das capacidades e habilidades perdidas ou não desenvolvidas ao longo da vida, motiva uma postura participativa, criativa e mais independente, tendo como foco principal o desenvolvimento da participação social e da organização das atividades cotidianas.

Descritores: Terapia Ocupacional. Transtornos da Alimentação. Anorexia Nervosa.

\section{1- INTRODUÇÃO}

Os transtornos alimentares têm sido foco da atenção dos profissionais da área da saúde pelo aumento da incidência na população adolescente e jovem, por apresentarem significativos graus de morbidade e mortalidade, acometendo na maioria, mulheres em idade fértil, escolar e produtiva. O prejuízo pessoal, social e cotidiano, o curso longo e variável e o prognóstico reservado, requerem ações multiprofissionais e planejamentos adequados para a prevenção e o tratamento dos transtornos alimentares.

A etiologia tem sido apresentada como sendo determinada por fatores biológicos, psicológicos e só- 
cio-culturais que interagem de modo complexo, desencadeando ou perpetuando a doença ${ }^{1}$. Na mesma direção, Gorgati et al. (2002) ${ }^{2}$ apontam que tais aspectos determinam as dimensões a serem abordadas no tratamento, ou seja, a necessidade de uma equipe multiprofissional e integrada, sobretudo em situações de hospitalização.

Lock et al. (2001)3 ; Lask e Bryant-Waugh $(2000)^{4}$ enfatizam em seus estudos que os melhores resultados parecem ocorrer nos casos onde a intervenção é precoce, evitando a cronificação e a instalação de formas mais graves e a assistência, composta por estratégias integradas de uma equipe multiprofissional.

Tais pressupostos embasam as ações da equipe do Grupo de Assistência em Transtornos Alimentares (GRATA) do Hospital das Clínicas da Faculdade de Medicina de Ribeirão Preto-USP (HCFMRP-USP) que desde o seu início, operou de forma multidisciplinar, contando desde 1999 com a presença do terapeuta ocupacional do Serviço de Terapia Ocupacional Hospitalar que realiza atendimento em Interconsulta à pessoas com anorexia nervosa internadas na Enfermaria de Nutrologia do referido hospital.

\section{2- AS DIFICULDADES COTIDIANAS VIVEN- CIADAS POR PESSOAS COM ANOREXIA NERVOSA}

As solicitações para a assistência da terapia ocupacional para pessoas com anorexia nervosa abrangem variadas situações, entre elas, a dificuldade de aceitação e de adesão ao tratamento por não se sentirem doentes e por evitarem o ganho de peso, queixas de ansiedade e dificuldade de permanecerem no ambiente hospitalar, história prévia de dificuldades no relacionamento interpessoal e nas atividades do dia-a-dia.

A clientela predominante atendida é constituída por mulheres adolescentes e jovens, em sua maioria, com dificuldade na organização e no desempenho das atividades da vida cotidiana, seja pelos comprometimentos clínicos ou pelos prejuízos emocionais e sociais. Não é raro apresentarem um cotidiano restrito, sendo comum afastamentos do trabalho, dificuldades nos relacionamentos interpessoais, na realização de atividades do dia-a-dia e em casos graves, a desvinculação dos papéis sociais e profissionais.

Gonzaléz et al. $(2001)^{5}$ avaliando 180 pessoas com diagnóstico de transtornos alimentares observa- ram que a qualidade de vida nesta população mostrou-se pior quando comparada à pessoas sem diagnóstico de anorexia nervosa ou outras doenças psiquiátricas, pareadas quanto ao sexo e a idade. Esse estudo mostrou ainda que as áreas mais afetadas nesta população são o funcionamento social e emocional e o desempenho físico, causando prejuízos na vitalidade, nas relações sociais e no bem estar geral, tanto pelas alterações clínicas, diminuição da auto-estima, sentimentos de ineficácia e inabilidade quanto pelo isolamento social.

Sobre isso, uma paciente relata: “...não sei se é da minha cabeça, mas eu não gosto de sair porque todo mundo fica olhando de um jeito esquisito ou então ficam insistindo para que eu coma junto com eles, eu não gosto".

Observa-se que pessoas com anorexia nervosa apresentam intensas falhas na comunicação, interpretação e verbalização de seus afetos e estados emocionais, assim como na percepção das sensações corporais $^{2}$. Na assistência da terapia ocupacional, observam-se também dificuldades relacionadas à autonomia, ao desempenho nas atividades escolares, prejuízos no trabalho pelos afastamentos e faltas, muitas vezes relacionadas às alterações clínicas e às relações interpessoais, como relatado a seguir:

“... não estou conseguindo trabalhar. Vou lá, mas tenho que ficar sentada porque sinto muita tontura e fraqueza, aí é pior porque todo mundo fica falando, eu sei que elas falam de mim. Parece até que faço corpo mole, mas não é isso, eu passo mal...".

Ou então: “...Odeio quando as meninas me levam comida e ficam insistindo pra eu comer... elas levam porque acham que eu tenho que comer, mas eu não consigo comer e as pessoas não entendem"

As dificuldades nas relações interpessoais prejudicam intensamente o bem estar no ambiente de trabalho, assim como na participação das atividades sociais e de lazer, tornando estas pessoas afastadas de amigos, familiares e também do trabalho ou da escola.

Em situações mais graves, as atividades cotidianas mostram-se desconstruídas e desorganizadas, não raro encontramos pessoas que referem passar a maior parte do dia em casa ou ainda na cama, relatam falta de vontade e dependência de familiares para algum passeio ou para acompanha-las em consultas. Uma paciente quando relatava um dia típico em sua vida conta: "fico só na cama, me sinto fraca e sem vontade de nada...". 
A preocupação com o comer ou o não comer é um tema central que preenche o pensamento e determina as ações cotidianas, mostrando um tempo não vivido, mas marcado pela preocupação constante com a comida, com o peso, as calorias, a dieta e, desta forma, tornando-as pessoas excluídas da participação de grande parte das atividades sociais.

Bidaud (1998, p.26) ${ }^{6}$, ressalta que a “...relação apaixonada da anoréxica com o objeto alimento, define um objeto ao mesmo tempo idolatrado e odiado, puro e impuro...estas pessoas não vivem mais, a não ser na espera ansiosa do objeto necessário..." .

\section{3- A ASSISTÊNCIA DO TERAPEUTA OCUPA- CIONAL PARA PESSOAS COM ANOREXIA NERVOSA}

Benetton (1994) ${ }^{7}$ conceitua o sujeito-alvo das ações da Terapia Ocupacional como aquele que está desinserido socialmente, localizando a doença e suas repercussões como provocadoras de um corte, uma interrupção ou ainda uma desconstrução no cotidiano. Focaliza o processo terapêutico e a conseqüente realização de atividades como possibilitador de novos rumos para o fazer, ressaltando que "a relação de ensinar, aprender, construir, inventar, criar, propiciada no fazer partilhado, abre espaço para a ocorrência de uma experiência individual prazerosa, onde fatos da vida são vividos de forma diferente".

Muitas vezes, é na terapia ocupacional que as pessoas com anorexia nervosa conseguem construir uma nova relação com seu fazer, por meio de planejar, organizar e realizar junto com o terapeuta suas ações cotidianas. Assim, uma paciente em sua fala diz: "aqui na TO eu não penso na comida, é o único momento que me distraio dela". A outra paciente reforça: "aprender fazer bijuterias me ajudou ter vontade de sair pra comprar materiais e depois, me ajudou perceber que tudo que fazia, parecia de criança. Agora estou fazendo umas mais de gente grande”.

Os primeiros projetos na terapia ocupacional, muitas vezes se iniciam pelo desejo e escolha do paciente de experimentar algo, provocado pelas atividades de pacientes do mesmo quarto, pela explicação do terapeuta sobre o que é possível fazer com cada material, pela observação das atividades prontas que o terapeuta leva como modelo ou ainda, pelo desejo de fazer o que fazia antes da doença. Foi com este desejo que uma paciente preenchia os encontros na terapia ocupacional com as lembranças dos "bolinhos de chuva" e outras comidas de sua infância, pois, "se o objeto alimento é temido, ele é ao mesmo tempo terrivelmente atraente" ${ }^{6}$. Esta paciente, 42 anos, com índice de massa corporal de $11,0 \mathrm{~kg} / \mathrm{m}^{2}$, preocupava a equipe pelo grande emagrecimento, pelos comprometimentos clínicos, a história antiga de anorexia nervosa e as restrições alimentares que se impunha. Neste momento, só comia alimentos pastosos em pequena quantidade (metade da colher de chá), fazia uso de sonda nasoentérica para completar as calorias necessárias, ingeria pequena quantidade de água e fazia uso crônico de laxativos diariamente. Estava afastada do trabalho há mais de um ano por dificuldades clínicas (fraqueza, tonturas, indisposição, mal estar geral). Seu cotidiano antes da internação era marcado pela permanência na cama, dependência extrema de familiares para sair de casa e para as decisões do dia-a-dia, ausência de amigos próximos e de projetos de lazer.

Nos primeiros contatos com o terapeuta ocupacional esta paciente dizia sentir-se confinada para "engorda" porque só comia, bebia e engordava, não podia andar, sentia-se mal. Contava-me nos primeiros encontros sobre sua adolescência, momentos bons de sua vida e das comidas que sua mãe fazia, entre elas, os "bolinhos de chuva" que agora não comia mais porque, segundo ela, "fritura engorda". Iniciando uma conversa sobre receitas culinárias, começamos um projeto com o nutricionista de fazermos estas comidas juntas e semanalmente a paciente decidia o que gostaria de comer e nos organizávamos com os ingredientes. Neste momento as comidas escolhidas tinham consistência pastosa, lembrando "papinhas de bebês", porém ao longo das semanas, passaram a ter aspecto de uma refeição e os encontros se transformaram em almoço acompanhado por sucos de frutas e mesa posta.

Oferecendo espaços de saúde, onde o fazer é compartilhado e sustentado pela relação terapêutica e posteriormente alcançando outras relações e espaços sociais, acreditamos que "a terapia ocupacional possa contribuir para a inserção social do sujeito que acontece num continuum que constitui e se dá com a construção cotidiana"8.

Ferrari e Tedesco $(2000)^{9}$ ressaltam que a construção do cotidiano interrompido pela doença e suas repercussões, implica diretamente em criar e vivenciar, do ponto de vista psicológico, espaços saudáveis 
no acontecer do dia-a-dia, permitindo que o indivíduo necessitado crie novamente uma relação individualizada com seu fazer e com aquilo que precisa ou quer realizar em seu cotidiano.

A entrada do paciente na terapia ocupacional é, na maioria das vezes, por ocasião de uma internação em hospitais gerais ou hospitais-dia, momento onde o quadro clínico está agravado, a pessoa apresenta intensas distorções da imagem corporal e seu cotidiano já está marcado por intensos prejuízos como perdas sociais, afastamentos, rupturas e distúrbios nos hábitos alimentares.

A assistência da terapia ocupacional para pessoas com anorexia nervosa pode contribuir para a diminuição do estresse do tratamento que coloca tais pacientes face àquilo que mais temem, ou seja, a necessidade de mudar hábitos alimentares e de ganhar peso, as mudanças corporais e a perda do controle sobre a ingestão de alimentos. Tendo em vista seu campo de conhecimento e de assistência, a terapia ocupacional proporciona um espaço de vivência e discussão para os conflitos relacionados à imagem corporal distorcida, ajuda no resgate das capacidades e habilidades perdidas ou não desenvolvidas ao longo da vida, motiva uma postura participativa, criativa e mais independente, abre espaços para que sentimen- tos possam ser expressados, vivenciados e percebidos pelo paciente, tendo como foco principal o desenvolvimento da participação social e da organização das atividades cotidianas.

\section{4- ALGUMAS CONSIDERAÇÕES FINAIS}

O processo terapêutico ocupacional para pessoas com anorexia nervosa vai assumindo diferentes significados a partir das histórias pessoais, no entanto, pode-se observar freqüentemente que o comer permeia todo o fazer, sendo a comida, o tamanho do corpo, o peso ou a estética corporal freqüentes temas para as atividades e desta forma, a terapia ocupacional torna-se um espaço internamente acolhedor e externamente possibilitador da ampliação das relações sociais e conseqüentemente, de despertar outras paixões além da comida.

Considerando as particularidades e necessidades apresentadas por cada indivíduo, a assistência da terapia ocupacional, criando espaços saudáveis no acontecer do dia-a-dia, permite que o indivíduo necessitado crie novamente uma relação individualizada com seu fazer e com aquilo que precisa ou quer realizar em seu cotidiano, podendo, portanto, contribuir no tratamento de pessoas com anorexia nervosa.

Morais LV. Assistance provided by the occupational therapist to persons with anorexia nervosa: reports of experience. Medicina (Ribeirão Preto) 2006; 39 (3): 381-5

ABSTRACT: Eating disorders are a subject of interest for health professionals because of their significant degrees of morbidity, mortality, and personal and social impairment.Since 1999, the occupational therapist of the Mental Health Inter-Consultation Service of the University Hospital, Faculty of Medicine of Ribeirão Preto-USP, has been providing assistance to patient with eating disorders admitted to the hospital. In most cases, this assistance is extended to the relatives and to the hospital team in order to perform joint and complementary actions in the various conflict situations. The clientele predominantly consists of adolescent and young women with signs and symptoms of anorexia nervosa, most of them having difficulty in organizing and performing daily living activities due to clinical, emotional and social impairment. These patients frequently present a restricted daily life, with absence from work, difficulty with interpersonal relationships and with daily activities and, in serious cases, with full detachment from their social and professional roles. On the basis of its field of knowledge and of its assistance, occupational therapy for persons with anorexia nervosa provides a space for experience and discussion regarding the conflicts related to a distorted body image, helps with the recovery of capacities and skills that have been lost or have not been developed along life, and motivates a participant, creative and more independent attitude mainly focused on the development of social participation and on the organization of daily activities.

Keywords: OcupationalTherapy. Eating Disorders. Anorexia Nervosa. 


\section{REFERÊNCIAS}

1 - Morgan MC, Vecchiatti IR, Negrão AB. A etiologia dos transtornos alimentares: aspectos biológicos, psicológicos e sócio-culturais. Rev Bras Psiquiatr 2002; 24 (Supl 3):18-23.

2 - Gorgati SB, Holcberg AS, Oliveira MD. Abordagem psicodinâmica no tratamento dos transtornos alimentares. Rev Bras Psiquiatr 2002; 24 (Supl 3): 44-8.

3 - Lock J, Le Grange D, Agras S.W, Dare C. Treatment manual for anorexia nervosa: a family-based approach. New York: The Guilford Press; 2001.

4 - Lask B, Bryant-Waugh R. Anorexia nervosa and related eating disorders in childhood and adolescence. 2nd. ed. London: Psychology Press; 2000.

5 - Gonzaléz N, Padierna JM, Aróstegui I, Horcajo MJ. Calidad de vida de los pacientes afectados de transtornos de alimentación. Gac Sanit 2001; 15:18-24.
6 - Bidaud É. Anorexia mental, ascese, mística: uma abordagem psicanalítica. Rio de Janeiro; Campanhia de Freud; 1998. p.5777: A tentação da anoréxica.

7 - Benetton MJ. A terapia ocupacional como instrumento nas ações de saúde mental. [Tese de Doutorado], Campinas: Faculdade de Ciências Médicas - UNICAMP; 1994. 190p.

8 - Takatori M. A terapia ocupacional no processo de reabilitação: construção do cotidiano. Mundo Saúde 2001; 25: 371-7.

9 - Ferrari SML, Tedesco AS. Acesso à teoria da técnica trilhas associativas. Rev Cent Est Ter Ocup 5: 32-6, 2000. 